Research Article

\title{
Competitive Failure of Loosening and Fatigue of Bolts under Composite Excitation
}

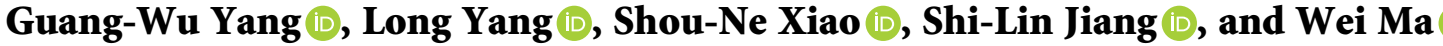 \\ State Key Laboratory of Traction Power, Southwest Jiaotong University, Sichuan, Chengdu 610031, China \\ Correspondence should be addressed to Long Yang; yanglong6788@163.com
}

Received 20 August 2021; Accepted 21 September 2021; Published 30 September 2021

Academic Editor: Lei Su

Copyright (C) 2021 Guang-Wu Yang et al. This is an open access article distributed under the Creative Commons Attribution License, which permits unrestricted use, distribution, and reproduction in any medium, provided the original work is properly cited.

At present, research on the loosening of bolts under transverse excitation and their fatigue under axial excitation has been relatively mature, but research on the competitive relationship and failure characteristics between loosening and fatigue of bolts under transverse and axial composite excitation is still insufficient. Therefore, a method to accurately determine the failure types of bolts is proposed in this study by conducting a competitive failure test of loosening and fatigue under composite excitation. According to this method, the failure types of bolts can be distinguished. The analysis results reveal that there is an obvious competitive failure relationship between the loosening and fatigue of bolts, and the failure mode is mainly affected by the ratio of the transverse and axial loads $(\xi)$. There is a critical $\xi$ of bolt-loosening or fatigue failure, and the critical $\xi$ is an inherent property of the bolt and is unrelated to the load. The critical $\xi$ of 8.8 grade $\mathrm{M} 8 \times 1.25 \times 70$ high-strength bolts under composite excitation is obtained as $0.075 \mathrm{~mm} / \mathrm{kN}$. The failure mode of bolts under composite excitation can be predicted based on the critical $\xi$.

\section{Introduction}

Bolt joints are widely used as fasteners in mechanical equipment, rail vehicles, automobiles, ships, the aerospace industry, and other fields owing to their simple structure, convenient disassembly, high efficiency, low cost, and stable and reliable fastening. However, the service environment of bolted connection structures is relatively complicated, and they are often subjected to loads such as vibration, impact, and temperature difference changes, which cause a reduction in the bolt clamping force and further cause bolt loosening [1]. In the initial stage of loosening, the normal operation of mechanical equipment may not be affected, but as the loosening further intensifies, the entire structure may fail, which may cause major safety production accidents [2]. Under the action of a high pretightening force and alternating load, high-strength bolts often experience fatigue fractures. As fatigue fracture is sudden, instantaneous, and difficult to prevent, for highstrength bolts, in addition to strict control of their mechanical properties and anticorrosion properties, their fatigue properties should also be strictly controlled [3]. The main failure modes of bolts are loosening failure caused by insufficient clamping force from loosening of bolt joints and fatigue fracture caused by the accumulation of bolt damage.

According to the different main force states of the bolts, the bolts can be divided into shear bolts, tension bolts, and tension-shear composite bolts. Under the action of a static force, the location of the shear-bolt failure is usually at the shear separation surface and the extrusion-bearing surface, whereas that of the tension bolt is at the minimum crosssection of the bolt. Under the action of a tensile-shear composite load, the failure location may also be at the maximum composite stress location [4]. Initially, Junker [5] designed a bolt transverse vibration testing machine. Through the bolt transverse vibration test, it was found that the transverse load was the main cause of bolt loosening. Later, Feng et al. [6] conducted fatigue tests of high-strength bolts under a tensile load and found that the axial load was the main cause of bolt fatigue. Since then, many experts and scholars have studied the failure of bolts mainly based on two aspects: loosening failure under a transverse load and fatigue failure under an axial load. 
In terms of loosening failure, based on Junker's transverse vibration testing machine, Jiang et al. [7, 8] obtained a boltloosening curve by conducting bolt-loosening tests under a transverse load. They divided the bolt-loosening process into two stages. The loosening during the first stage is caused by material deformation, and there is no relative rotation between the bolt and the nut. The loosening during the second stage is caused by the relative rotation of the nut, which is manifested as a rapid decrease in the clamping force. On this basis, $\mathrm{Mu}$ [9] divided the bolt-loosening process into three stages: initial, near-critical, and self-loosening. He proposed judgment conditions for the frictional looseness of highstrength bolts under cyclic loading. Zhang [10] studied the influence of the pretightening force, transverse amplitude, and vibration frequency on bolt loosening by conducting bolt-loosening tests under transverse loads. The results revealed that the amplitude is the main factor affecting bolt loosening, followed by the pretightening force, and the frequency has the weakest effect. Wang [11] established an accurate finite element model of a bolt with threaded angles. Through simulation, he found that the greater the impact load amplitude and pitch, the more easily the bolts will loosen. There is an initial pretightening force range and a range of friction coefficients of the thread-engaging surface that can make the bolt looseness the least likely to occur. Based on simulation of a three-dimensional finite element model of a bolt joint, Gong et al. [12] found that there is a critical transverse load for bolt loosening under a transverse load and that the bolt will not loosen when it is less than this value. Therefore, He et al. [13] proposed a theoretical formula for calculating the critical loosening displacement of bolts, but the calculation accuracy was not high. To compensate for the lack of high accuracy, Zhang et al. [14] derived a new numerical calculation formula for the critical loosening load of bolts under a transverse load. The calculated result matches the experimental value with a small error, which verifies the accuracy and reliability of the numerical calculation method. Gao et al. [15] established a finite element model of a bolt by considering its structural characteristics and material plasticity. Through simulation, they obtained the critical loosening law and critical loosening displacement of bolts under different transverse amplitudes and, finally, verified the reliability of the results through tests. In addition, Jiang et al. [16] studied the influence of displacement, velocity, and acceleration amplitude on bolt-loosening life through bolt transverse vibration tests and found that the transverse displacement amplitude is the main factor affecting bolt loosening. He then drew the bolt-loosening displacement-life (D-N) curve with reference to the stress-life (S-N) curve of the material and found that the D-N curve is similar to the S-N curve and also has the characteristics of double straight lines and high- and low-cycle boundaries. Yang et al. [17] studied the mechanism of bolt-loosening accumulation by conducting bolt high-low and low-high transverse variable-amplitude vibration tests and established a linear accumulation model of bolt loosening similar to the material fatigue linear accumulation criterion. Based on the bolt-loosening D-N curve and the bolt looseness linear accumulation model, the bolt looseness life can be predicted.
In terms of bolt fatigue failure, when the bolt stress or the axial stress generated by the bolt (caused by the load and prying force) is $<30 \%$ of the bolt tensile strength, the bolt axial stress barely changes, and the fatigue effect can be ignored. When the bolt stress exceeds $30 \%$ of the bolt tensile strength, a fatigue check should be performed [18]. The fatigue strength of bolts is often checked based on the VDI 2230-2003 standard, mechanical design methods, and nonlinear finite element methods [19]. Wang et al. [20] obtained the fatigue S-N curve of a bolt by conducting tensile and shear tests on stainless-steel bolts at a constant amplitude. Ouyang [21] used two S-N curve methods to estimate the fatigue life of high-strength bolts, combined with an equal life curve to comprehensively consider the effects of stress amplitude and stress ratio, and deduced the design formula for bolt fatigue. Based on the material damage accumulation criterion, Shi [22] studied the influence of the pretightening force and thread structure on the fatigue life of bolts and determined the best pretightening torque range of high-strength bolts and the best root radius of threads. Through testing, Zhao [23] found that the load distribution on screw threads is uneven, with $\sim 1 / 3$ of the load being concentrated on the first thread and the first three threads bearing $70 \%$ of the total load. Zhai [4] considered the contribution of tensile stress and shear stress to fatigue when calculating bolt fatigue and improved the selection method of reference stress in bolt fatigue life by introducing equivalent tensile stress. For the fatigue performance of bolt joints in unlubricated and lubricated states, Chakherlou et al. [24] found that the pretightening force increases the fatigue life of the bolt. However, when the pretightening force is lower than a certain critical value, the fatigue life stops improving owing to the fretting wear of the bolt. In the lubricated state, the improvement effect of the pretightening force on the fatigue life of the bolt is reduced.

When the bolt is subjected to composite excitation, there is a load or load component along the bolt axis, which increases the positive pressure between the contact surfaces of each connection. The increase in the positive pressure causes the frictional force between the contact surfaces to increase, and as the contact surfaces are not prone to relative sliding, the ability of the bolt connection to resist sliding increases, reducing the possibility of bolt loosening [25]. At present, few studies have been conducted on the failure of bolts that are simultaneously subjected to tension-shear composite excitation. Under normal conditions, the bolted connection structure was loosened before fatigue fracture occurred, and the bolt-loosening process was accompanied by the accumulation of bolt damage. Therefore, loosening and fatigue do not occur independently of each other. There was an interacting relationship between the two. During the entire life period, there is a competitive relationship between these two failure modes, which ultimately causes the product to fail.

The above-mentioned research has made significant contributions to the failure mechanism of bolt loosening and fatigue, numerical calculation methods, experimental methods, finite element simulation methods, failure evaluation methods, and failure influencing factors. However, 
research on the competitive relationship and characteristics between loosening and fatigue failure under composite excitation is still insufficient. Bolts are often used under composite excitation. Therefore, it is necessary to study the competitive failure characteristics of bolts under composite excitation to obtain a criterion for accurately predicting the failure mode of bolts, which is convenient for predicting the failure mode and failure life of bolt joints.

Based on the competitive failure test of loosening and fatigue, the competitive relationship and characteristics between loosening and fatigue failure under composite excitation are investigated in this study. A criterion for accurately predicting the failure mode of bolts is proposed. Based on this criterion, the failure modes of the bolts are distinguished. Based on the analysis results, the critical ratio of the transverse and axial loads $(\xi)$ for distinguishing the failure modes of bolts and the influence law of the load on the bolt competitive failure relationship are summarized. Finally, the bolt fracture analysis revealed the competitive failure mechanism of the bolt, providing a useful reference for engineering applications.

\section{Competitive Failure Test}

Because transverse excitations mainly lead to loosening and axial excitations mainly lead to fatigue, a competitive failure test of loosening and fatigue under tension-shear composite excitation of high-strength bolts was conducted to study the competitive failure characteristics of bolt joints. As shown in Figure 1, the test was conducted on an MTS tensile torsion fatigue testing machine. High-strength bolts of 8.8 grade $\mathrm{M} 8 \times 1.25 \times 70$ were used; the clamping force was collected by the pressure sensor in the test; and the test frequency was $10 \mathrm{~Hz}$. To convert torque into shear force, the fixture was designed as a disk-shaped symmetrical structure. To ensure that the load was not eccentric, two bolt specimens were installed at the symmetrical position of the fixture during each test. To ensure that the bolt holes of the fixture were centered after the bolts were tightened, two centering grooves were symmetrically opened on the sides of the fixture, and the centering blocks were aligned with the centering grooves when the bolts were tightened.

The mechanical design standard formulated by $\mathrm{Wu}$ and $\mathrm{Mu}$ [26] indicated that the pretightening stress of the bolt should not exceed $80 \%$ of its yield strength. However, in practical engineering applications, $60 \%-70 \%$ of the bolt yield strength is generally selected. In this study, the pretightening force was defined when the pretightening stress reached $60 \%$ of the yield strength, and the initial pretightening force of the 8.8 grade $\mathrm{M} 8 \times 1.25 \times 70$ highstrength bolts was obtained as $14.1 \mathrm{kN}$. The combinations of the composite excitations of the specimens are listed in Table 1. The tensile and shear loads were applied in a sinusoidal form with a phase difference of $90^{\circ}$. The tensile load ratio was 0 , and the shear load ratio was -1 . Since the testing machine can directly output tension force and torque and the form of torque converted into shear force through discshaped fixture is displacement, the unit of axial load is $\mathrm{kN}$, and the unit of the transverse load is $\mathrm{mm}$.
Figure 2 shows the recession curves of the clamping force of the bolts obtained through the test. The typical bolt clamping force recession curve can be divided into three stages: material loosening, structural loosening, and fatigue fracture. During the material loosening period, plastic deformation of the material causes the bolt clamping force to decline rapidly, and the nut does not rotate. During the period of structural loosening, the clamping force of the bolts steadily declined owing to the relatively stable rotation of the nut. During the fatigue fracture period, the damage accumulation approached the fatigue limit of the bolt. At this time, the bolt cracks, which caused the bolt fatigue fracture, and the clamping force dropped sharply to zero. The bolt failure process is intuitively expressed in these three stages, but loosening and fatigue are not independent processes. Loosening occurs from the beginning, and the material loosening period and structural loosening period are also accompanied by the accumulation of bolt fatigue damage. There was an interaction between the loosening and fatigue of the bolt. Under a large transverse load and small axial load, the structural loosening period of the bolt clamping force recession curve became shorter and steeper; the loss of clamping force became larger; the fatigue fracture period was relatively smooth; and the bolt failure process appeared as an obvious loosening process. Under a small transverse load and large axial load, the structural loosening period of the bolt clamping force recession curve became longer and smoother; the loss of clamping force became smaller; the fatigue fracture period was relatively steep; and the bolt failure process appeared as an obvious fatigue process. Therefore, there is a competitive failure relationship between loosening and fatigue according to different load forms.

Because the clamping force recession curve exhibits a continuous and smooth decay process, the relevant research has not revealed a clear and unified method for dividing the three stages so far. To distinguish between the material loosening period and the structural loosening period, Wang [27] used the node where the bolt torsional deformation rebound was 0 to characterize the speed of the elastic torsional deformation of the bolt and the beginning of the obvious rotation of the nut relative to the bolt. This was taken as the demarcation point between the material loosening period and the structural loosening period. Jiang et al. [8] defined a nut rotation angle of $0.5^{\circ}$ as the dividing point between the material loosening period and the structural loosening period. Jiang [28] found that when the slope of the clamping force recession curve reached $45^{\circ}$, the bolt entered the fatigue fracture period, which was used as the demarcation point between the structural loosening period and the fatigue fracture period. In this study, to distinguish between the structural loosening period and the fatigue fracture period, competitive failure tests were conducted. These tests also revealed that the intersection of the clamping force recession curve and the $45^{\circ}$ tangent (point $N_{2}$ in Figure 2) could be used as the dividing point between the structural loosening period and the fatigue fracture period. Before the intersection point, the bolt exhibits an obvious loosening process; after the intersection point, it exhibits an obvious fatigue fracture process. For high-strength bolts fabricated with a relatively hard material, the loosening during the 


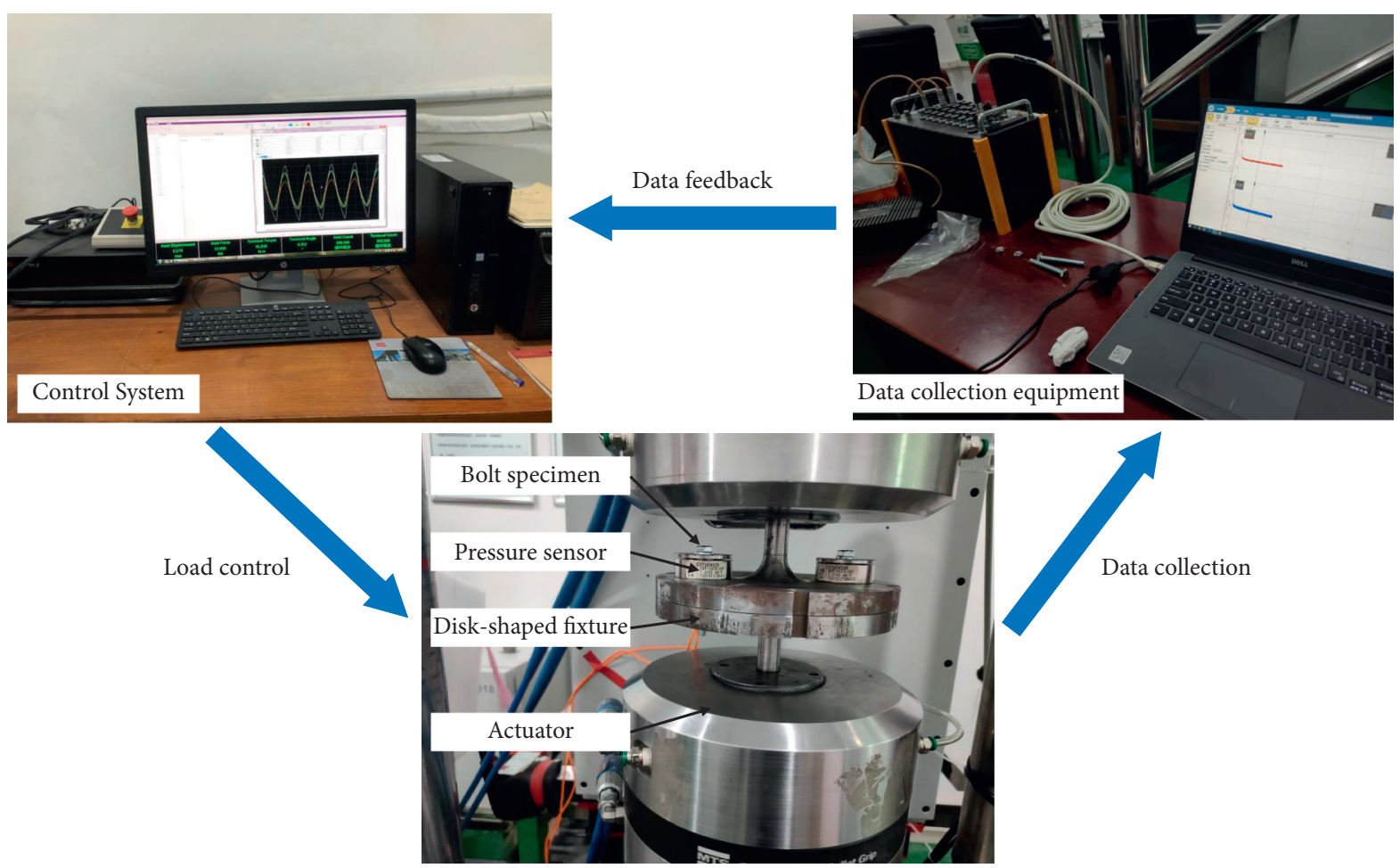

Figure 1: Schematic diagram of the test system.

TABLE 1: Combinations of composite excitation in competitive failure tests.

\begin{tabular}{|c|c|c|c|}
\hline Transverse displacement amplitude $(\mathrm{mm})$ & Axial load amplitude $(\mathrm{kN})$ & $\xi(\mathrm{mm} / \mathrm{kN})$ & Number of valid specimens \\
\hline 0.5 & 0 & - & 2 \\
\hline 0.5 & 5 & 0.1 & 3 \\
\hline 0.5 & 6 & 0.0833 & 3 \\
\hline 0.5 & 8 & 0.0625 & 3 \\
\hline 0.6 & 0 & - & 2 \\
\hline 0.6 & 2 & 0.3 & 5 \\
\hline 0.6 & 4 & 0.15 & 5 \\
\hline 0.6 & 6 & 0.1 & 3 \\
\hline 0.6 & 8 & 0.075 & 3 \\
\hline 0.6 & 9.6 & 0.0625 & 3 \\
\hline 0.6 & 10 & 0.06 & 3 \\
\hline 0.7 & 0 & - & 3 \\
\hline 0.7 & 2 & 0.35 & 3 \\
\hline 0.7 & 5 & 0.14 & 3 \\
\hline 0.7 & 7 & 0.1 & 3 \\
\hline 0.7 & 8 & 0.0875 & 3 \\
\hline 0.7 & 9 & 0.0778 & 3 \\
\hline 0.7 & 11.2 & 0.0625 & 3 \\
\hline 0.8 & 0 & - & 2 \\
\hline 0.8 & 2 & 0.4 & 3 \\
\hline 0.8 & 4 & 0.2 & 3 \\
\hline 0.8 & 6 & 0.1333 & 3 \\
\hline 0.8 & 8 & 0.1 & 3 \\
\hline 0.8 & 10 & 0.08 & 3 \\
\hline 0.8 & 12 & 0.0667 & 3 \\
\hline 0.8 & 12.8 & 0.0625 & 3 \\
\hline 0.9 & 0 & - & 3 \\
\hline 0.9 & 2 & 0.45 & 3 \\
\hline 0.9 & 4 & 0.225 & 3 \\
\hline 0.9 & 6 & 0.15 & 3 \\
\hline 0.9 & 9 & 0.1 & 3 \\
\hline
\end{tabular}


TABLE 1: Continued.

\begin{tabular}{lccc}
\hline Transverse displacement amplitude $(\mathrm{mm})$ & Axial load amplitude $(\mathrm{kN})$ & $\xi(\mathrm{mm} / \mathrm{kN})$ & Number of valid specimens \\
\hline 0.9 & 14.4 & 0.0625 & 3 \\
1.0 & 0 & - & 1 \\
1.0 & 1 & 0.5 & 3 \\
1.0 & 2 & 0.25 & 3 \\
1.0 & 4 & 0.1 & 3 \\
1.0 & 10 & 0.0833 & 2 \\
1.0 & 12 & 0 & 1 \\
0 & 12 & & 3 \\
\hline
\end{tabular}

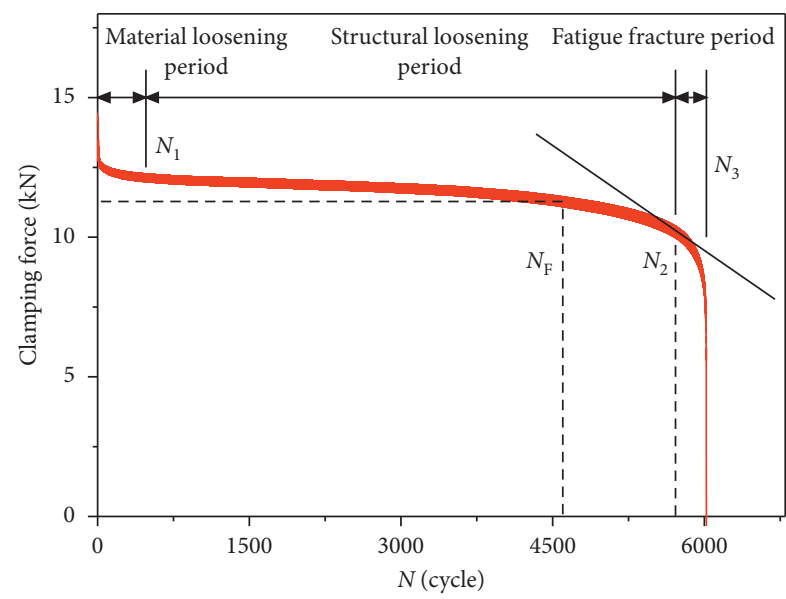

Figure 2: Typical clamping force recession curve.

material loosening period only accounts for a small part of the total cycles, and the clamping force is reduced by $\sim 10 \%$. When the clamping force dropped to $80 \%$ of the pretightening force, the bolt entered the structural loosening period. At this time, a certain angle of rotation of the nut causes significant loosening [7,8]. Therefore, $80 \%$ of the pretightening force (point $N_{\mathrm{F}}$ in Figure 2) was defined as the criterion for significant bolt loosening in this study. If the bolt is in the structural loosening period, its clamping force drops to $80 \%$ of the pretightening force, that is, $N_{\mathrm{F}}<N_{2}$, and the bolt failure is considered to be loosening failure. If the bolt is in the fatigue fracture period, its clamping force drops to $80 \%$ of the pretightening force, that is, $N_{\mathrm{F}}>N_{2}$, and the bolt failure is considered to be fatigue failure [29].

According to the excitation and boundary condition in the test, the solid finite element model of the bolt joint was established by HyperMesh software, as shown in Figure 3. The $z$-axis was the axis direction of the screw, and the $x$-axis and $y$-axis were the transverse directions of the screw. The geometry of the model was consistent with the specimen, and the element type was set to solid 185 . Four contact pairs of bolt head-upper plate, upper plate-lower plate, nut-lower plate, and screw thread-nut thread were established, and the friction coefficient was set to 0.2 . The boundary conditions were as follows: the upper plate of the clamped parts constrained the translational degrees of freedom in $x, y$, and $z$ directions. The lower plate only constrained the translational degrees of freedom on the $x$-axis and applied axial excitation on the $z$-axis and transverse excitation on the $y$-axis. The material of bolt and nut were set to bilinear elastic-plastic steel, and the material parameters are shown in Table 2. The preload elements were set on the nodes in the middle of the bolt, and the value of preload was $14.1 \mathrm{kN}$. The load and load ratio applied by the lower plate are shown in Table 1. The failure criteria of bolts refer to Category 50 of the fatigue strength classification in EN 1993-1-9 standard [30], and the $\mathrm{S}-\mathrm{N}$ relationship can be described as follows:

$$
\Delta \sigma^{3} N=2.5 \times 10^{11},
$$

where $[\Delta \sigma]_{2.5 \times 10^{6}}=50 \mathrm{~N} / \mathrm{mm}^{2}$.

As shown in Figure 4, all fractured bolts exhibited two fracture forms: fracture at the transition fillet along the bolt head and fracture at the first thread of the bolt working thread. Take the stress nephogram under the load of $0.6 \mathrm{~mm}-10 \mathrm{kN}$ as an example, all the fractured positions are consistent with the stress concentration positions, and the fracture surfaces are the cross-sections where the bolts are in contact with the clamped parts. The tensile and shear loads were applied in a sinusoidal form with a phase difference of $90^{\circ}$. The axial tensile load reached a maximum when the bolt returned to the zero position after the maximum shear load was reached. The axial load caused the bolt to generate uniform tensile stress, but the shear load maximized the shear stress of the two cross sections. Under the action of the composite excitation, the fatigue damage of the bolt accumulated at the two cross sections, which eventually led to fatigue fracture (the stress nephogram is the simulation result under the load of $0.6 \mathrm{~mm}-10 \mathrm{kN}$ ).

\section{Analysis of Bolt Competitive Failure}

3.1. Relationship of Competitive Failure. The competitive failure test data for the specimens under composite excitation in Table 1 are summarized to compare the clamping force recession curves under the same axial load $(2 \mathrm{kN})$ and the same transverse load $(0.6 \mathrm{~mm})$, as shown in Figure 5 . It can be seen that under the same axial load, the life of the bolt gradually decreases with an increase in the transverse load. The length and steepness of the material loosening period, structural loosening period, and fatigue fracture period of different clamping force recession curves are obviously different. The greater the transverse load, the greater the plastic deformation of the bolt material, and the faster the clamping force decreases during the material loosening period, that is, the shorter and steeper the material loosening period. Similarly, as the transverse load increases, the nut rotates faster and more violently during the structural 


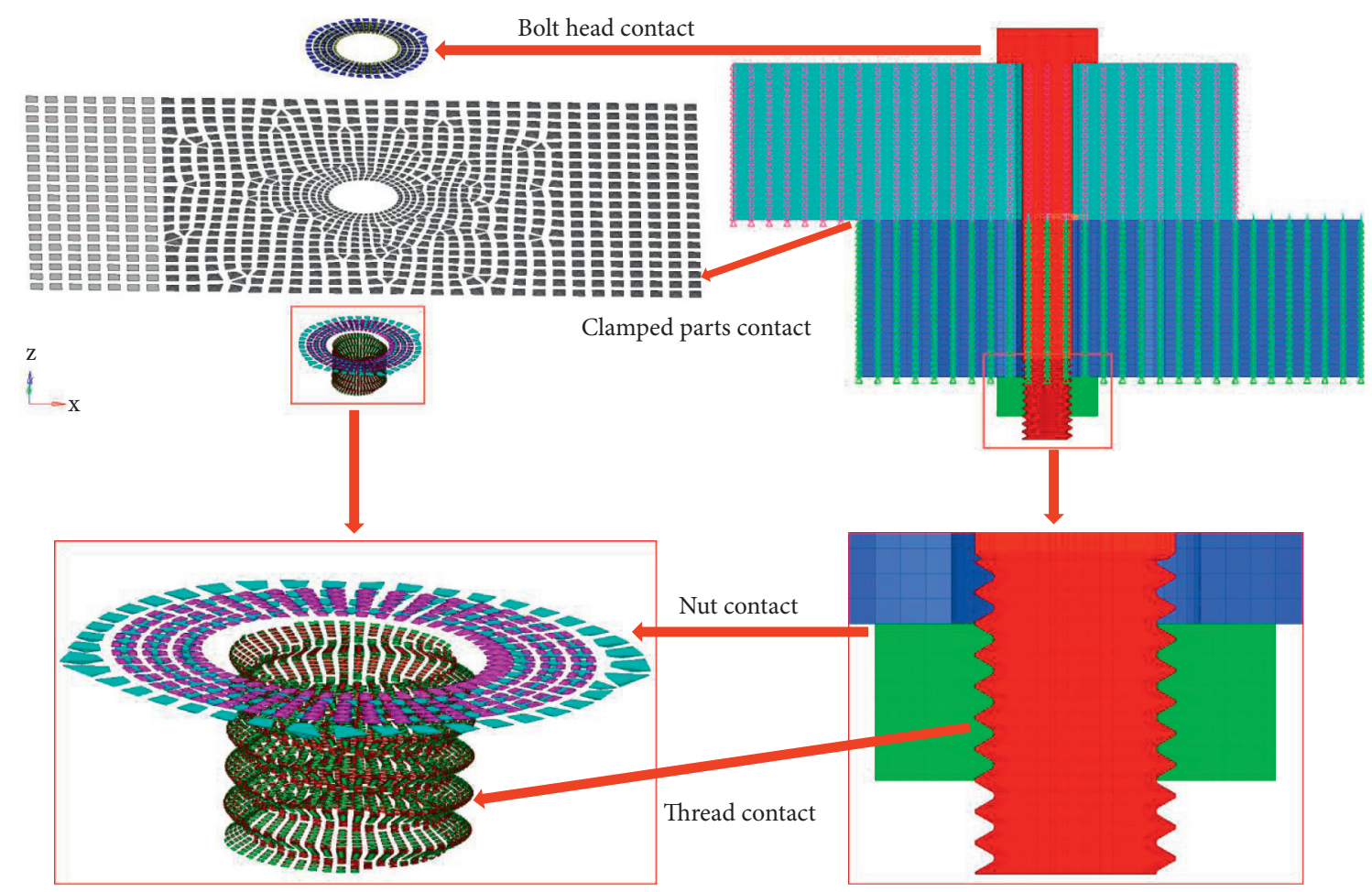

FIGURE 3: Finite element model of bolt joint.

TABLE 2: Material parameters.

\begin{tabular}{lccccc}
\hline Young's modulus $(\mathrm{MPa})$ & Poisson's ratio & Yield strength $(\mathrm{MPa})$ & Tangent modulus $(\mathrm{MPa})$ & Tensile strength $(\mathrm{MPa})$ & $\mathrm{Density}\left(\mathrm{g} / \mathrm{cm}^{3}\right)$ \\
\hline 205,000 & 0.3 & 640 & 22,500 & 900 & 7.85
\end{tabular}

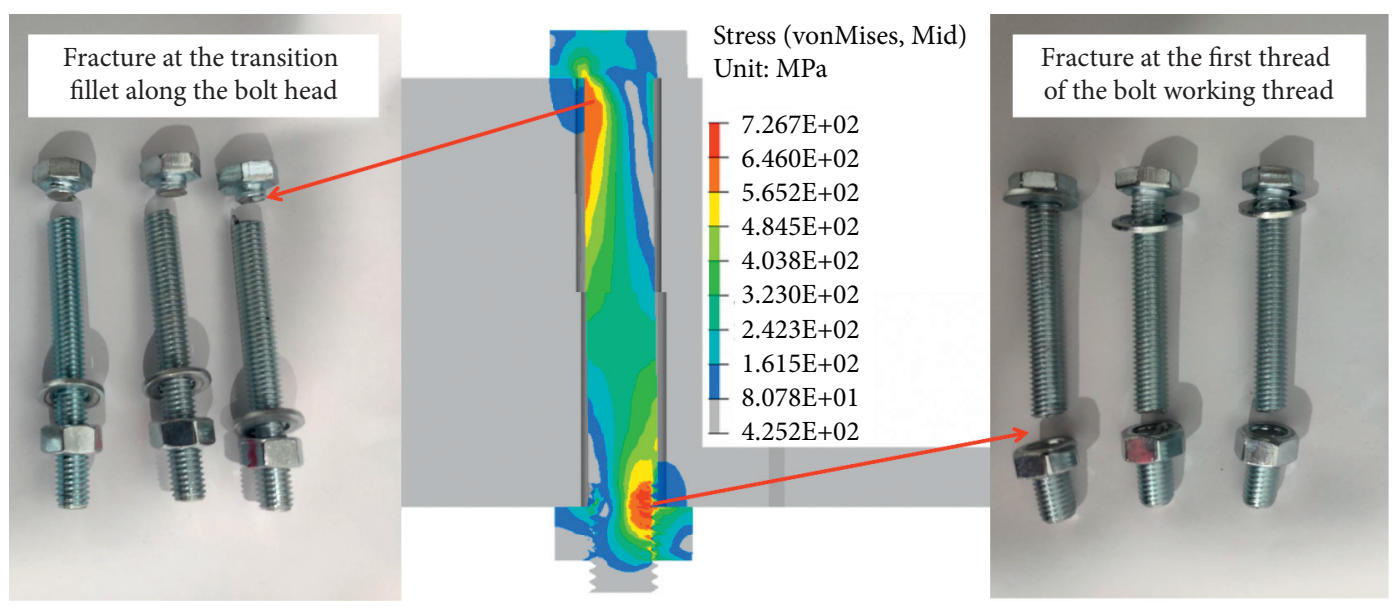

FIGURE 4: Comparison of fractured bolts and their simulation stress.

loosening period, which leads to a faster decline in the bolt clamping force and an increase in the slope of the curve. The greater the transverse load, the greater the transverse shearing force of the bolt, and the greater the stress amplitude in the stress concentration area at the root of the thread, which leads to faster bolt fatigue and shorter life. It can be seen that there is an obvious competitive failure between the loosening and fatigue of the bolt.
Under the same transverse load, as the axial load increased, the life of the bolt first increased and then decreased, indicating that a small axial load restrained loosening. As the axial load increases, the failure mode of the bolts changes from loosening failure to fatigue failure, and the effect of the axial load also changes from restraining loosening to aggravating fatigue. This is because, when a single lateral load is applied, there is only a pretightening force along the bolt axis. The positive pressure on 


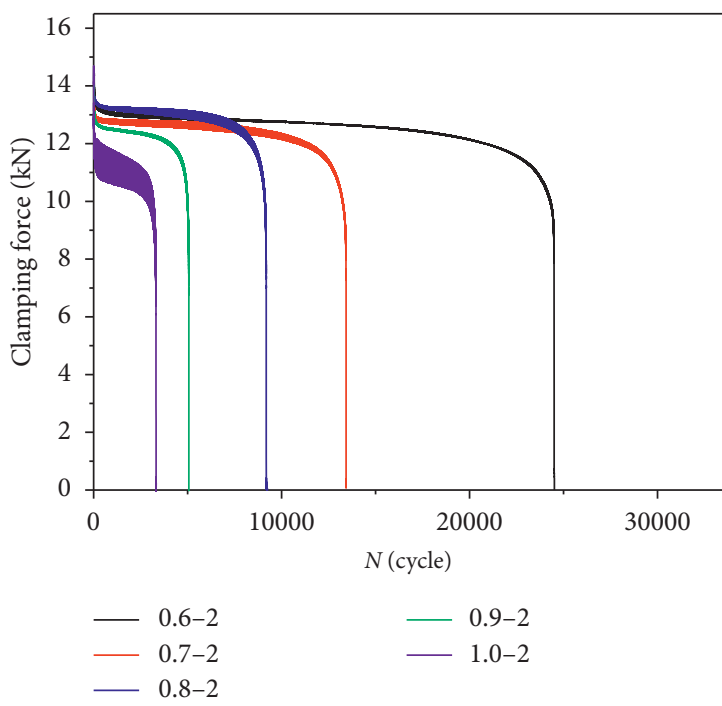

(a)

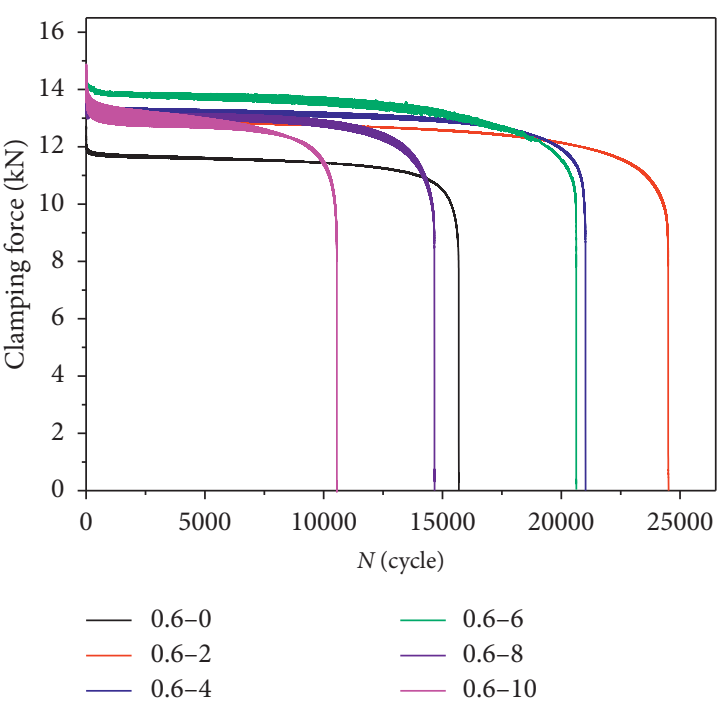

(b)

FIGURE 5: Comparison of clamping force recession curves under different loads: (a) under the same axial load and (b) under the same transverse load.

the contact surface was low, and the pretightening force was lost as the number of cycles increased, which made the bolt prone to loosening failure. When the composite excitation was applied, there was a load component along the bolt axis, which increased the positive pressure on the connecting contact surface, resulting in an increase in the friction between the contact surfaces. The contact surface is less prone to relative sliding, and the ability of the bolt connection to resist sliding is increased, the bolt is not easy to loosen, and the service life is relatively long [24]. A small axial load increases the friction between the contact surfaces, thus increasing the life of the bolt. However, under the action of a large axial load, the composite stress of the bolt will be very large, resulting in a large plastic deformation of the thread and a shorter fatigue life of the bolt. Therefore, there is a critical value for the axial load that restrains failure. When the axial load is less than the critical value, the axial load has a suppressing effect; when it is greater than the critical value, it has a promoting effect. It can be seen from Table $3\left(N_{0.6 \_8}\right.$ is the bolt life with an axial load of $6 \mathrm{kN}$ and a transverse load of $8 \mathrm{kN}$ ) that the critical value of the axial load for the restraining failure of the bolt under a transverse load of $0.6 \mathrm{~mm}$ is $\sim 7.65 \mathrm{kN}$. The length and steepness of the material loosening period, structural loosening period, and fatigue fracture period under the same transverse load are also significantly different. The basic trend is that as the axial load increases, the rate at which the clamping force decreases in the three stages first decreases and then increases. This trend is related to the small axial loads restraining bolt failure. When the axial load is less than the critical value, as the axial load increases, the rate at which the clamping force decreases in the three stages gradually drops. When the axial load was greater than the critical value, as the axial load increased, the rate at which the clamping force decreases in the three stages gradually increases. This phenomenon again demonstrates that there is an obvious competitive failure relationship between the loosening and fatigue of the bolt.
3.2. Critical Competitive Failure Ratio. The test results for all bolt specimens under composite excitation in Table 1 are distinguished according to the criterion of bolt failure type in Figure 2, and the clamping force recession curve of a typical failure bolt can be obtained, as shown in Figure 6. It can be seen that the failure modes of the bolts exhibit obvious differences with the change in $\xi$. When $\xi$ is large, the bolts exhibit obvious loosening failure; when $\xi$ is small, they exhibit obvious fatigue failure. Therefore, there is a clear competitive failure relationship for bolts under composite excitation, and there is a critical $\xi$ leading to bolt-loosening or fatigue failure. When the actual $\xi$ is greater than the critical $\xi$, bolt-loosening failure will occur, and when the actual $\xi$ is less than the critical $\xi$, fatigue failure of the bolts will occur. It can also be seen from Figure 6 that with the increase in $\xi$, the variation in the interval between $N_{\mathrm{F}}$ and $N_{2}$ is large-small-large, and the variation of the failure type is fatigue failure-critical competitive failure-loosening failure.

The competitive failure modes of all bolts under composite excitation are listed in Table 4 . It can be seen that when $\xi>0.075 \mathrm{~mm} / \mathrm{kN}$, the bolts all exhibit loosening failure and, when $\xi<0.075 \mathrm{~mm} / \mathrm{kN}$, the bolts all exhibit fatigue failure. Therefore, the critical $\xi$ for loosening or fatigue failure of 8.8 grade $\mathrm{M} 8 \times 1.25 \times 70$ high-strength bolts under composite excitation is $0.075 \mathrm{~mm} / \mathrm{kN}$. As shown in Figures 6(a) and 6(c), the greater the difference between the actual $\xi$ and critical $\xi$, the more obvious is the bolt failure mode. As shown in Figure 6(b), the smaller the difference between the actual $\xi$ and critical $\xi$, the less obvious the bolt failure mode. In addition, under different loads, as long as the actual $\xi$ is greater than the critical $\xi$, the bolts will exhibit loosening failure, and the bolts will exhibit fatigue failure when the actual $\xi$ is less than the critical $\xi$. This demonstrates that the critical $\xi$ is an inherent property of the bolt, which is related to the bolt material, size, and assembly method but is independent of the load size. For a bolt joint under a given 
TABLE 3: Calculation of the critical value of the axial load for restraining bolt failure.

\begin{tabular}{|c|c|c|c|c|}
\hline $\begin{array}{l}\text { Transverse displacement } \\
\text { amplitude }(\mathrm{mm})\end{array}$ & $\begin{array}{l}\text { Axial load } \\
\text { amplitude }(\mathrm{kN})\end{array}$ & $\begin{array}{c}N \\
\text { (cycles) }\end{array}$ & $\begin{array}{l}\text { Effect of axial load } \\
\text { on bolt failure }\end{array}$ & $\begin{array}{l}\text { The critical value of the axial load for restraining bolt failure } \\
\qquad(\mathrm{kN})\end{array}$ \\
\hline 0.6 & 0 & 15,690 & - & \multirow{6}{*}{$(8-6)\left(\left(N_{0.6_{-} 6}-N_{0.6_{-} 0}\right) /\left(N_{0.6_{-} 6}-N_{0.6_{-} 8}\right)\right)+6=7.65$} \\
\hline 0.6 & 2 & 24,515 & Restraining & \\
\hline 0.6 & 4 & 21,021 & Restraining & \\
\hline 0.6 & 6 & 20,631 & Restraining & \\
\hline 0.6 & 8 & 14,666 & Promoting & \\
\hline 0.6 & 10 & 10,560 & Promoting & \\
\hline
\end{tabular}

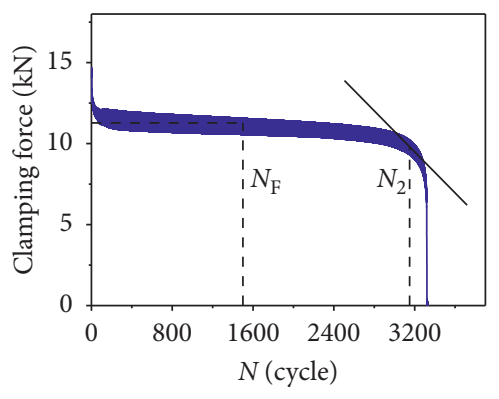

$1.0-2, \xi=0.5$

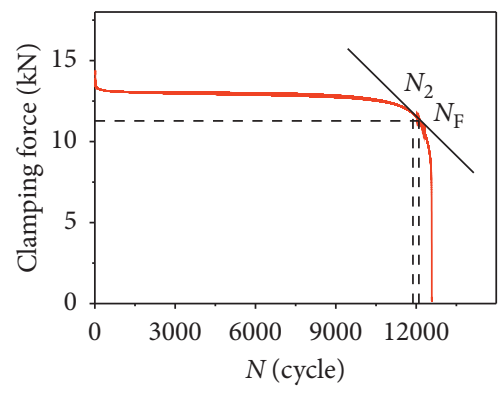

$-0.6-8-1, \xi=0.075$

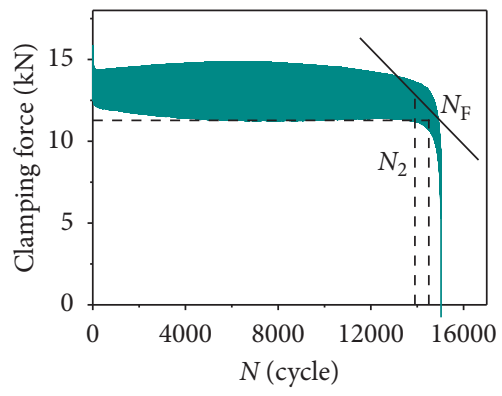

$0.7-11.2, \xi=0.0625$

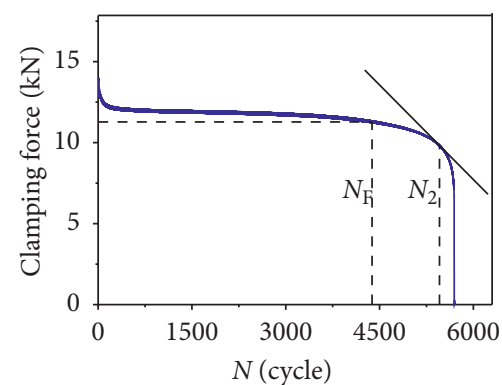

$-0.8-4, \xi=0.2$

(a)

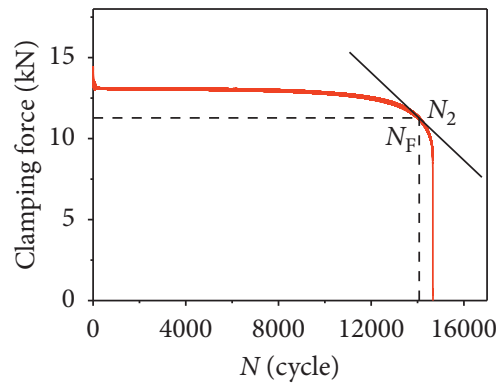

$-0.6-8-2, \xi=0.075$

(b)

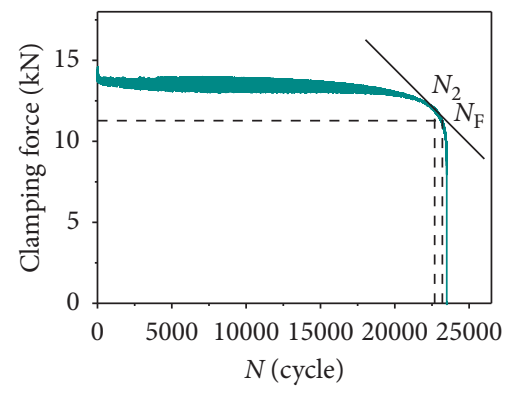

$0.6-9.6, \xi=0.0625$

(c)

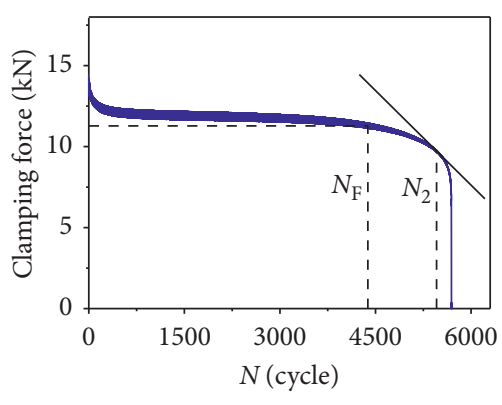

$0.8-6, \xi=0.13$

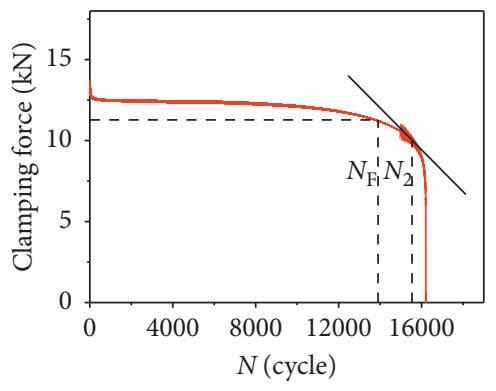

$0.6-8-3, \xi=0.075$

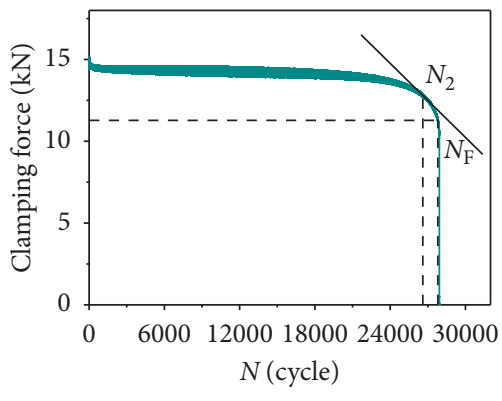

— $0.5-8, \xi=0.0625$

FIGURE 6: Comparison of clamping force recession curves with different failure modes: (a) loosening failure curves, (b) critical competitive failure curves, and (c) fatigue failure curves. 
TABLE 4: Analysis results for bolt competitive failure modes.

\begin{tabular}{|c|c|c|c|}
\hline Transverse displacement amplitude $(\mathrm{mm})$ & Axial load amplitude $(\mathrm{kN})$ & $\xi(\mathrm{mm} / \mathrm{kN})$ & Failure mode \\
\hline- & - & $>0.1$ & Loosening \\
\hline 0.6 & 6 & 0.1 & Loosening \\
\hline 0.6 & 6 & 0.1 & Loosening \\
\hline 0.6 & 6 & 0.1 & Loosening \\
\hline 0.7 & 8 & 0.0875 & Loosening \\
\hline 0.7 & 8 & 0.0875 & Loosening \\
\hline 0.7 & 8 & 0.0875 & Loosening \\
\hline 1 & 12 & 0.0833 & Loosening \\
\hline 1 & 12 & 0.0833 & Loosening \\
\hline 0.5 & 6 & 0.0833 & Loosening \\
\hline 0.8 & 10 & 0.08 & Loosening \\
\hline 0.8 & 10 & 0.08 & Loosening \\
\hline 0.8 & 10 & 0.08 & Loosening \\
\hline 0.7 & 9 & 0.0778 & Loosening \\
\hline 0.7 & 9 & 0.0778 & Loosening \\
\hline 0.7 & 9 & 0.0778 & Loosening \\
\hline 0.6 & 8 & 0.075 & Fatigue \\
\hline 0.6 & 8 & 0.075 & Critical \\
\hline 0.6 & 8 & 0.075 & Loosening \\
\hline 0.8 & 12 & 0.0667 & Fatigue \\
\hline 0.8 & 12 & 0.0667 & Fatigue \\
\hline 0.8 & 12 & 0.0667 & Fatigue \\
\hline 0.9 & 14.4 & 0.0625 & Fatigue \\
\hline 0.9 & 14.4 & 0.0625 & Fatigue \\
\hline 0.9 & 14.4 & 0.0625 & Fatigue \\
\hline 0.8 & 12.8 & 0.0625 & Fatigue \\
\hline 0.8 & 12.8 & 0.0625 & Fatigue \\
\hline 0.8 & 12.8 & 0.0625 & Fatigue \\
\hline 0.7 & 11.2 & 0.0625 & Fatigue \\
\hline 0.7 & 11.2 & 0.0625 & Fatigue \\
\hline 0.7 & 11.2 & 0.0625 & Fatigue \\
\hline- & - & $<0.0625$ & Fatigue \\
\hline
\end{tabular}

composite excitation, the failure type and life of the bolt can be predicted based on the critical $\xi$, which provides a reference for engineering applications.

\section{Fracture Analysis}

As shown in Figure 4, the bolt fractures along the transition fillet of the bolt head or along the first thread of the bolt working thread under a composite cyclic load. From a macro point of view, the main reason for the bolt fracture is the stress concentration at these two positions of the bolt. Under the action of the composite cyclic load, the stress amplitude of these two positions is the highest, and the accumulation of fatigue damage leads to fatigue fracture of the bolt. From a micro point of view, the bolt experienced two stages of crack generation and crack propagation before fatigue fracture. The fatigue life is the sum of the crack formation life and the propagation life [31]. Under the action of the composite cyclic load, microcracks were produced at the positions of stress concentration. Under the continuous action of the alternating stress, the cracks gradually propagated and eventually caused the bolt to fracture.

To further analyze the propagation law of bolt fatigue cracks and the mechanism of competitive failure, a scanning electron microscope was used to observe the bolt fracture.
Figure 7 shows the comparison of macrofracture morphology and simulation stress of the bolts under a pure axial load of $0 \mathrm{~mm}-12 \mathrm{kN}$ (Mode I, fatigue failure), a composite load of $0.6 \mathrm{~mm}-8 \mathrm{kN}$ (Mode II, critical competition failure), and a pure transverse load of $0.6 \mathrm{~mm}-0 \mathrm{kN}$ (Mode III, loosening failure). Since the static stress cannot reflect the fatigue damage accumulation and crack growth process of the bolt, but it can directly reflect the stress concentration position of the bolt, so the stress concentration position of the bolt can be seen according to the simulation stress. The dynamic stress is constantly changing with the external load, which can reflect not only the stress concentration position of the bolt but also the fatigue damage accumulation and crack propagation process of the bolt. Because the dynamic stress was inconvenient to directly monitor, it was analyzed through the fracture morphology of the bolt. It can be seen that the position of the stress concentration is located at the fracture of the bolt, and the macrofracture morphology of the bolt has (a) an obvious crack source zone, (b) a crack propagation zone, and (c) an instantaneous fracture zone, which is the typical fatigue fracture. After the bolt is subjected to the pulsation of the external force, microcracks are first generated at the transition fillet of the bolt head or the thread root where the stress concentration is serious, and finally, the fatigue crack source is formed [32]. Multiple 

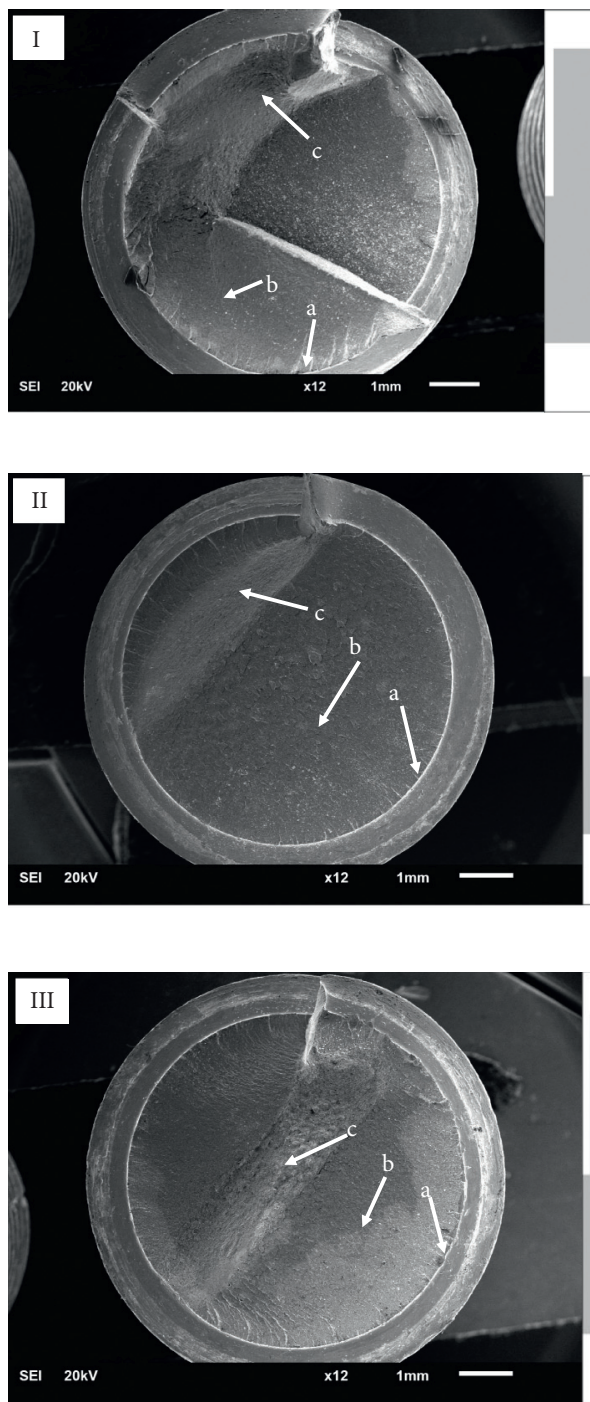

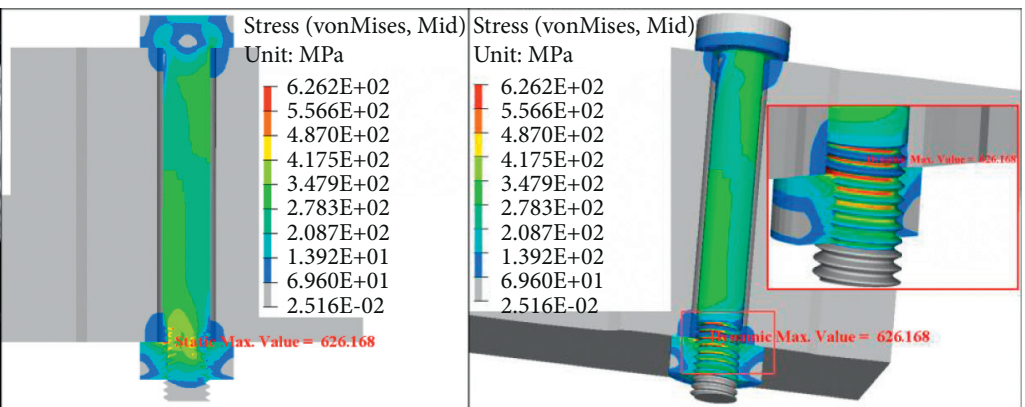

(a)

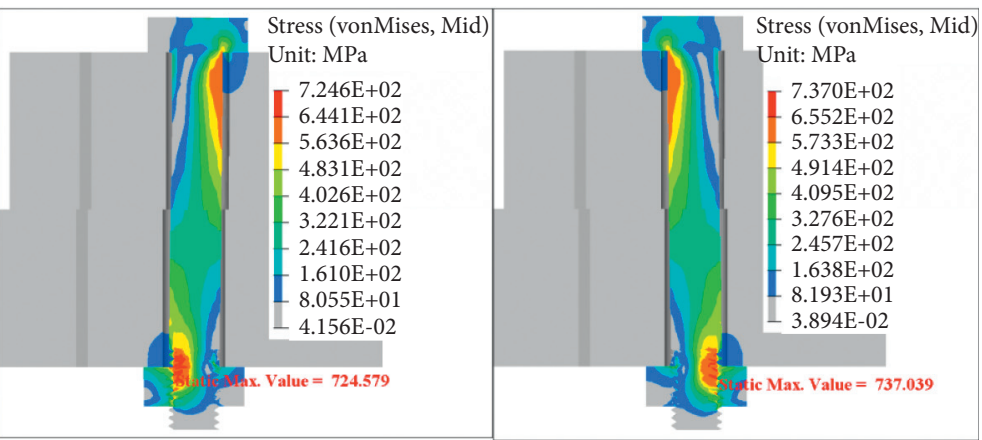

(b)
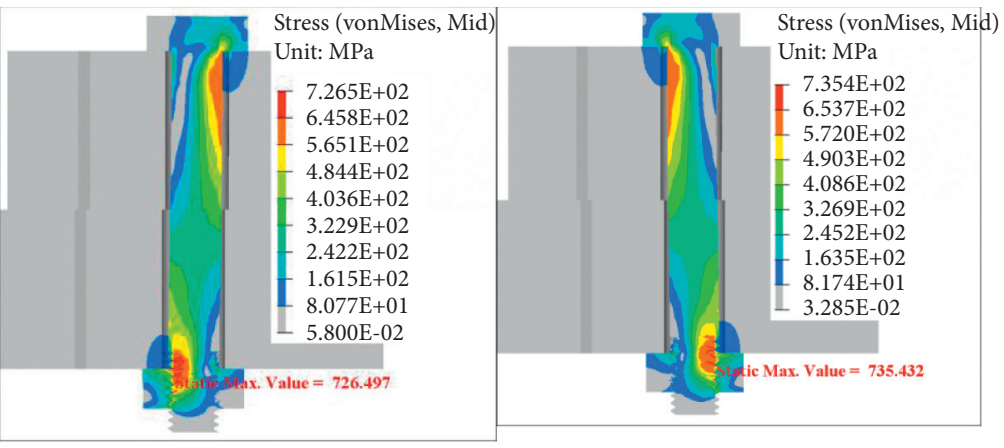

(c)

Figure 7: Comparison of macromorphology of bolt fracture and simulation stress: (a) Mode I, (b) Mode II, and (c) Mode III.

crack sources are concentrated in the circumferential direction of the bolt fracture and spread radially; therefore, the bolt fracture is the typical failure of a multicrack source. Because the bolt has multiple crack sources and the thread has a helical angle, tearing steps with different sizes are formed at the junction of different zones of the fracture.

Because of the different load forms, both the macromorphologies of the bolt fracture and stress concentration position exhibit obvious differences. As shown in Figure 7(a), the Mode I (fatigue failure) bolt is only subjected to uniform tensile stress. Because the thread has a helix angle, the stress is concentrated on one side of the first circle of the working thread. The crack sources were generated on one side of the bolt circumferential direction, and the cracks continued to propagate to the other side until the bolt fractured. Therefore, the instantaneous fracture zone is located on the opposite side of the crack source zone, and the crack propagation zone is located between the crack source zone and the instantaneous fracture zone. As shown in
Figure 7(c), there is stress concentration on both sides of the first circle of the bolt working thread of Mode III (loosening failure) bolt. The crack sources were evenly distributed across the entire circumference of the bolt, and the propagation speed was basically the same. The instantaneous fracture zone was distributed in the center of the fracture, and the propagation zone was symmetrically distributed on both sides of the instantaneous fracture zone. As shown in Figure 7(b), there is stress concentration on both sides of the first circle of the bolt working thread of Mode II (critical competitive failure) bolt under the action of transverse load, but the stress on one side of the thread becomes larger due to the axial load, so there are crack sources in the entire circumference of the bolt fracture, and the cracks on one side propagate faster. Compared with Mode I fracture, the instantaneous zone of Mode II moved a certain distance to the center of the fracture.

The reasons for the above phenomenon are: after cracks are produced on one side of the bolt under a pure axial load, 

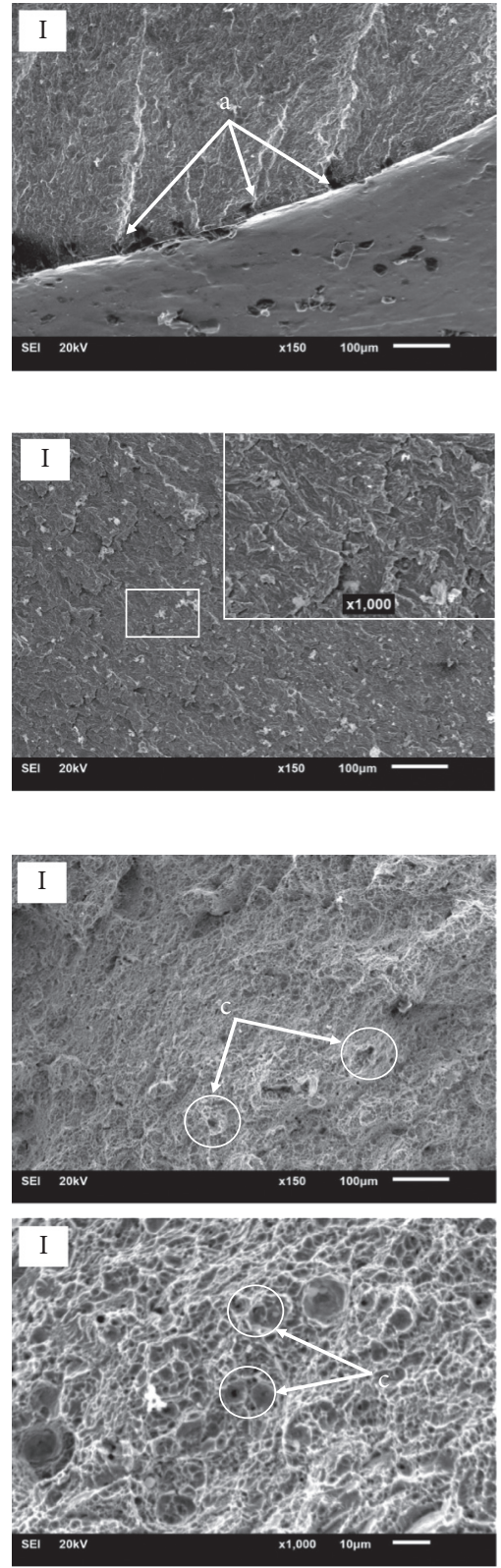
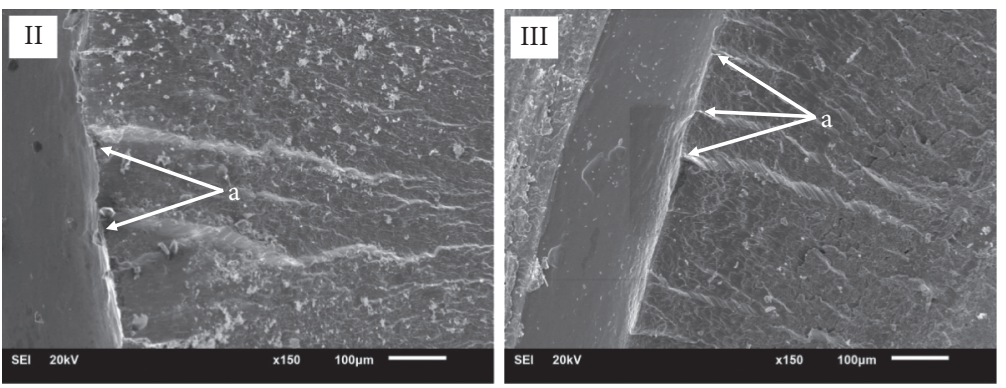

(a)
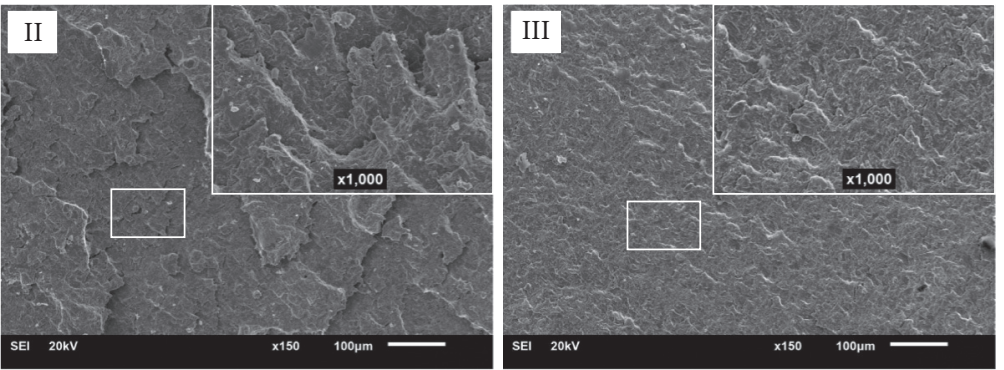

(b)
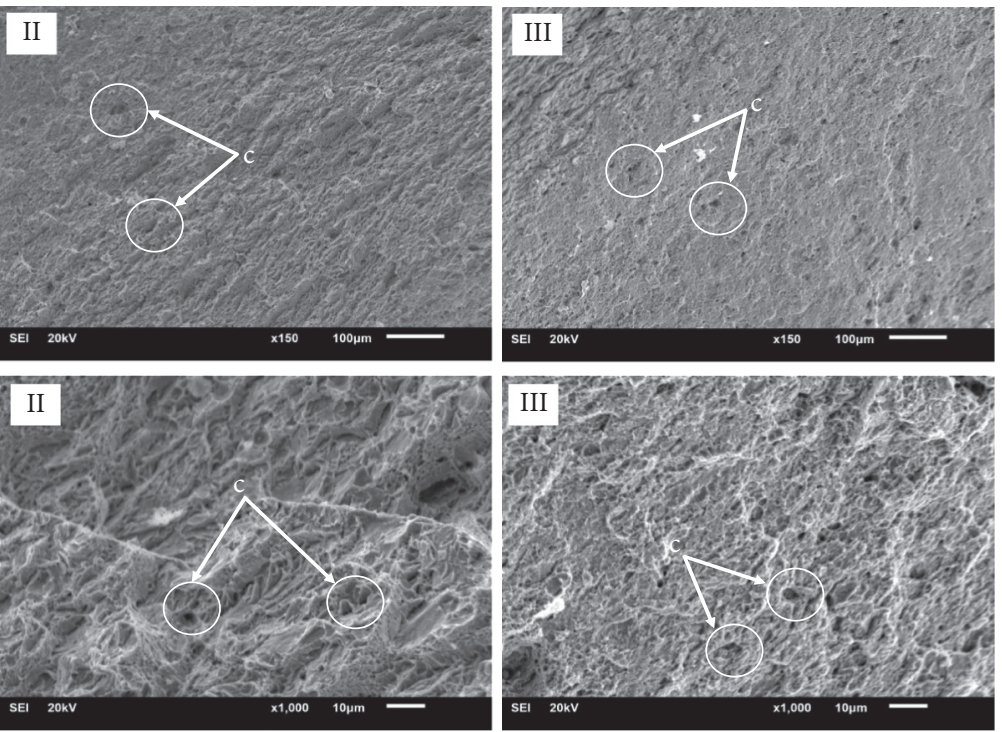

(c)

FIGURE 8: Micromorphology of bolt fracture: (a) crack source zone, (b) crack propagation zone, and (c) instantaneous fracture zones.

the cracks propagate in the depth direction and on both sides under the cyclic action of tensile stress. The tensile area of the bolt gradually changed, and the axial load was eccentric when the crack on the other side did not occur; consequently, the crack continued to propagate from one side to the other side until the bolt fractured. Owing to the superposition of the eccentric load and helical angle, the fracture step of the Mode I fracture is relatively obvious. The bolts bear only the shear stress under a pure transverse load. Because the shear load ratio is -1 , the shear stresses on the two sides of the bolt are equal, and there is stress concentration. The circumferential cracks steadily propagate to the center, and, finally, instantaneous fracture occurs at the center. The instantaneous fracture zone of Mode II was located between the instantaneous fracture zones of Modes I and III. Mode II bolts bear both tensile and shear stresses, such that the fracture exhibits both a unilateral crack propagation trend and stable crack propagation characteristics. The crack propagation rates on the two sides of the fracture are also significantly different, which proves that there is a competitive relationship between bolt loosening and fatigue.

The micromorphology was observed at higher magnification, as shown in Figure 8. The crack source zone is relatively flat and bright because of the slow propagation rate of the crack in the crack source zone and the repeated extrusion and friction on the crack surface. In addition, the crack source zone has obvious shell ridges extending to the 
inside in a wave shape, and there are obvious crack initiation steps at the crack initiation sites. The sizes and smoothness of the crack propagation zone are different, and there are fatigue striations, fine white ligaments, and a few secondary cracks. The instantaneous fracture zone is small and rough, and a shear lip is often formed at the end. There are tearing traces left by a sudden fracture in the instantaneous fracture zone, exhibiting obvious brittle fracture characteristics. Numerous loose dimples were observed throughout the instantaneous fracture zone.

Owing to the different load forms, the micromorphologies of the bolt fractures also exhibited obvious differences. The crack source of Mode III fracture is more severely worn than that of Mode I fracture, and the ridge morphology is not obvious. This is because there is basically no wear on the fracture surface of Mode I bolts under pure axial load with a stress ratio of 0 , whereas Mode III bolts are repeatedly scratched and worn under cyclic shear loads, and the surface has a porcelain-like structure. Because Mode II is subjected to composite loads, shear stress causes scratches and wear, whereas tensile stress restrains wear. As a result, the degree of wear for the Mode II crack source is lower than that of Mode III, which is between Modes I and III. The crack propagation zone of Mode I fracture is smaller and rougher, and there are more and clearer fatigue striations and white ligaments. In contrast, the crack propagation zone of Mode III is larger and smoother, and there are fewer and more fuzzy fatigue striations and white ligaments. This results from the scratch effect of shear stress, which causes severe wear on the fracture, forming a smooth flaky area. The crack propagation zone of Mode II is between that of Modes I and III. It exhibits the rough characteristics of plastic deformation caused by tensile stress and the smooth flake characteristics of friction and wear caused by shear stress. Mode I fracture exhibits numerous equiaxed dimples in the instantaneous fracture zone, whereas Mode III fractures have shear dimples. Mode II fractures have two types of dimples at the same time. The plastic deformation of the material caused by tensile stress makes Mode I dimples larger, deeper, and irregular, and the friction and wear caused by the shear stress make Mode II dimples smaller, shallower, and more regular.

It can be seen from the above that the micromorphology of Mode II fracture has both the plastic deformation characteristics of Mode I fracture and the wear characteristics of Mode III fracture. This proves once again that there is a competitive relationship between the loosening and fatigue of the bolt. It can also be seen that the presence of tensile stress under a composite load will restrain the degree of wear from shear stress; that is, the degree of bolt loosening is suppressed by the axial load. This proves the conclusion drawn in Figure 5(b): a small axial load restrains bolt loosening, and there is a critical value of axial load that restrains failure under composite excitation.

\section{Conclusion}

In this study, by conducting a competitive failure test of loosening and fatigue of bolts under composite excitation, the mechanism of the competitive failure of loosening and fatigue, the failure law, and the failure prediction method were revealed. The following conclusions can be drawn based on the results obtained:

(1) There is a severe stress concentration at the transition fillet of the bolt head and the first thread of the bolt working thread under a composite cyclic load, which makes the two positions most likely to fracture.

(2) The intersection point $\left(\mathrm{N}_{2}\right)$ of the bolt clamping force recession curve and the $45^{\circ}$ tangent can be used as the demarcation point between the structural loosening period and the fatigue fracture period. A value of $80 \%$ of the pretightening force $\left(N_{\mathrm{F}}\right)$ can be used as the criterion for significant bolt loosening. The failure type of the bolt can be determined according to the relative positions of $N_{\mathrm{F}}$ and $\mathrm{N}_{2}$.

(3) The failure mode of bolts is mainly affected by $\xi$, and there is a critical $\xi$ leading to bolt-loosening or fatigue failure. The greater the difference between the actual $\xi$ and critical $\xi$, the more obvious is the distinction of failure modes. In engineering, the failure mode of bolts can be predicted according to the critical $\xi$.

(4) The critical $\xi$ for loosening failure or fatigue failure of 8.8 grade $\mathrm{M} 8 \times 1.25 \times 70$ high-strength bolts under composite excitation is $0.075 \mathrm{~mm} / \mathrm{kN}$. The critical $\xi$ is an inherent property of the bolt that is related to the bolt material, size, and assembly method; it is independent of the load size.

(5) Fracture analysis shows that under composite excitation, the bolt undergoes both plastic deformation under tensile load and wear under shear load, and the two have a competitive relationship depending on the load form.

Limited by the amount of test data, the precise demarcation point of the structural loosening period, the fatigue fracture period, and the judgment criterion of significant loosening have not been obtained. These aspects need to be further investigated through supplementary tests. In the future, the law of axial small load restraining loosening and the influence of the pretightening force on bolt competitive failure should also be studied.

\section{Data Availability}

The data used to support the findings of this study are given in the tables and figures within the manuscript.

\section{Conflicts of Interest}

The authors declare that there are no conflicts of interest.

\section{Acknowledgments}

This work was supported by the National Natural Science Foundation of China (51675446) and the Independent Subject of State Key Laboratory of Traction Power (2019TPL-T13). 


\section{References}

[1] M. M. Tang, A Study of Loosening Process of Stainless Steel Bolt and Method for Resisting Loosening under Transverse Loading, Southwest Jiaotong University, Chengdu, China, 2018.

[2] J. Liu, H. Ouyang, J. Peng et al., "Experimental and numerical studies of bolted joints subjected to axial excitation," Wear, vol. 346-347, pp. 66-77, 2016.

[3] Z. L. Zeng and X. J. Feng, "Research and discussion on fatigue performance evaluation method of high strength bolts," Internal Combustion Engine \& Parts, vol. 292, no. 16, pp. 35-36, 2019.

[4] X. K. Zhai, "Discussion and research of the calculation method for the fatigue life of the bolt," Manufacturing Automation, vol. 38, no. 1, pp. 89-91, 2016.

[5] G. H. Junker, "New criteria for self-loosening of fasteners under vibration," SAE Transactions, vol. 78, pp. 314-335, 1969.

[6] X. J. Feng, X. S. Lin, W. Pan, Y. Qin, and B. S. Huang, "Fatigue behavior of space grid with bolt sphere joints under suspended crane loading," Journal of Building Structures, vol. 16, no. 4, pp. 3-12, 1995.

[7] Y. Jiang, M. Zhang, and C. H. Lee, "A study of early stage selfloosening of bolted joints," Journal of Mechanical Design, vol. 125, no. 3, pp. 518-526, 2003.

[8] Y. Jiang, M. Zhang, T.-W. Park, and C.-H. Lee, "An experimental study of self-loosening of bolted joints," Journal of Mechanical Design, vol. 126, no. 5, pp. 925-931, 2004.

[9] J. Mu, Experimental Research on Fatigue Failure of Connecting Nodes with High-Strength Bolts, Chongqing Jiaotong University, Chongqing, China, 2010.

[10] Y. B. Zhang, Experimental Study on Looseness of Bolt Connection Structure under Transverse Vibration Condition, Xinjiang University, Urumchi, China, 2018.

[11] K. P. Wang, Research on Factors Affecting Bolt Loosening under Impact Load, Shenyang University of Technology, Shenyang, China, 2019.

[12] H. Gong, J. H. Liu, and X. Y. Ding, "Study on the critical loosening condition toward a new design guideline for bolted joints," Proceedings of the Institution of Mechanical Engineers Part C: Journal of Mechanical Engineering Science, vol. 233, no. 9, pp. 3302-3316, 2019.

[13] J. F. He, T. Tang, and C. S. Wang, "Finite element research on self-loosening problem of bolt connection under the alternating lateral load," Modern Manufacturing Engineering, vol. 3, pp. 1-6, 2016.

[14] M. Y. Zhang, L. T. Lu, M. M. Tang, and D. Zeng, "Research on numerical calculation method of critical load for bolt loosening under transverse loading," Journal of Mechanical Engineering, vol. 54, no. 5, pp. 173-178, 2018.

[15] X. S. Gao, T. M. Zhou, and Y. M. Mo, "Research on critical loose displacement load of bolts under transverse vibration," Mechanical Engineering \& Automation, vol. 4, pp. 22-24, 2019.

[16] S. L. Jiang, G. W. Yang, S. N. Xiao, and C. Wang, "Experimental study on the loosening life of bolts," Journal of Mechanical Strength, vol. 41, no. 5, pp. 1060-1065, 2019.

[17] G. Yang, C. Che, S. Xiao, B. Yang, T. Zhu, and S. Jiang, "Experimental study and life prediction of bolt loosening life under variable amplitude vibration," Shock and Vibration, vol. 2019, Article ID 2036509, 8 pages, 2019.

[18] S. L. Wen, S. Tian, and Z. X. Hou, "Brief introduction of revised contents of technical specification for high strength bolt connections of steel structures," Building Structure, vol. 44, no. 7, pp. 89-92, 2014.

[19] X. F. Li, R. Sun, and K. C. Yan, "Study on strength analysis method of bolts in standardized EMU equipment bay," Journal of Dalian Jiaotong University, vol. 41, no. 1, pp. 29-34, 2020.

[20] J. Wang, B. Uy, D. Li, and Y. Song, "Fatigue behaviour of stainless steel bolts in tension and shear under constantamplitude loading," International Journal of Fatigue, vol. 133, Article ID 105401, 2020.

[21] Q. Ouyang, High Strength Bolt Stress and Fatigue Performance Study, Hunan University, Changsha, China, 2013.

[22] H. Shi, Research of High Strength Bolt Failure Caused by Several Factors, Northeastern University, Shenyang, China, 2012.

[23] H. Zhao, "Analysis of the elasto-plastic stress in a screwedpipe joint," Journal of Mechanical Engineering, vol. 1, pp. 87-92, 1997.

[24] T. N. Chakherlou, M. J. Razavi, A. B. Aghdam, and B. Abazadeh, "An experimental investigation of the bolt clamping force and friction effect on the fatigue behavior of aluminum alloy 2024-T3 double shear lap joint," Materials \& Design, vol. 32, no. 8-9, pp. 4641-4649, 2011.

[25] P. C. Zhang, Experimental Investigation on Self-Loosening Mechanism for Bolted Joints under the Transverse Loading, Zhejiang University of Technology, Hangzhou, China, 2018.

[26] Z. Z. Wu and L. M. Wu, Mechanical Design, China Railway Publishing House, Beijing, China, 2016.

[27] C. H. Wang, Analysis and Experimental Study on Loosening Characteristics of Bolted Connections, Dalian University of Technology, Dalian, China, 2018.

[28] S. L. Jiang, Experimental Study on Bolt Loosening and Competing Failure between Loosening and Fatigue, Southwest Jiaotong University, Chendu, China, 2020.

[29] L. Yang, B. Yang, G. Yang et al., "Analysis of competitive failure life of bolt loosening and fatigue," Engineering Failure Analysis, vol. 129, Article ID 105697, 2021.

[30] European Committee for Standardization, EN 1993-1-9: Eurocode 3: Design of Steel Structures, Part 1-9: Fatigue, European Committee for Standardization, Brussels, Belgium, 2005.

[31] D. M. Yang, Mechanical Properties and Failure Analysis of Metals, Metallurgical Industry Press, Beijing, China, 1991.

[32] G. F. Sun, P. B. Ren, and X. Zhang, "Fracture analysis of the high-strength steel bolts," Mechanical Engineering, vol. 12, pp. 32-34, 2015. 